\title{
Water absorption and thickness swelling properties of silica aerogel infused sugar palm fiber/polyester composites
}

\author{
R. M. Shahroze, M. R. Ishak, M. Asim, M. Chandrasekar, M. T. Paridah, M. Jawaid
}

\begin{abstract}
Using natural fibres as reinforcements in composites provides an inexpensive green alternate to its synthetic counterpart. In a similar scope, to enhance the usability of sugar palm fibres (SPF) in composites, various weight percentages $(1 \%$ to 5\%) of silica aerogel (SA) were infused in SPF reinforced unsaturated polyester composites. The samples were prepared using hand layup procedure followed by hot pressing at $80^{\circ} \mathrm{C}$ for 30 minutes. The physical properties such as water absorption and thickness swelling characteristics of the composites were investigated. The specimen of water absorption and thickness swelling were exposed to water absorption for a total of 90 days and measured on alternate days in first week. Later, the readings were taken on a weekly basis until the 3rd week and bi-weekly for the rest of immersion time. Pure SPF composites showed lowest water absorption and thickness swelling and it increased with addition of SA. The highest water absorption was recorded up to $12 \%$ and thickness swelling was $7 \%$ in $5 \%$ SA composites. SA showed its hydrophilicity character, but the percentage of water absorption and thickness swelling is very less.
\end{abstract}

Index Terms: Sugar palm fibres; Polyester; silica aerogel; water absorption and thickness swelling.

\section{INTRODUCTION}

Natural fibres are used in various products such as textile, paper, packaging, etc., due to their low density, renewability, biodegradability, abundance, and low cost, which make them an ideal raw material for these applications [1]. Use of these fibres can also result in reduction of dependence on its synthetic counter parts, which are a grave threat to the environment these days. Most of the natural fibres are considered as waste material and are abundantly available worldwide [2,3]. Natural fibres have many advantages over the synthetic fibres such as minimal health hazards, low density, high flexibility, non-abrasive nature, low energy consumption for manufacturing and low production cost [4].

Revised Manuscript Received on July 05, 2019.

R. M. Shahroze, Department of Aerospace Engineering, Universiti Putra Malaysia, Serdang, Selangor, Malaysia

M. R. Ishak, Department of Aerospace Engineering, Universiti Putra Malaysia, 43400 Serdang, Selangor, Malaysia

M. Asim, Institute of Tropical Forestry and Forest Products (INTROP), Universiti Putra Malaysia, Serdang, Selangor, Malaysia. Corresponding author.Email:asimkhan@upmedu.my

M. Chandrasekar, Department of Aerospace Engineering, Universiti Putra Malaysia, 43400 Serdang, Selangor, Malaysia

M.T. Paridah, Institute of Tropical Forestry and Forest Products (INTROP), Universiti Putra Malaysia, Serdang, Selangor, Malaysia.

M. Jawaid, Institute of Tropical Forestry and Forest Products (INTROP), Universiti Putra Malaysia, Serdang, Selangor, Malaysia. Corresponding author.Email: jawaid@upmedu.my
Several studies have been studied based on natural fibres reinforced thermoset and thermoplastic composites [5,6].

Although there are benefits, there are some disadvantages associated with the use of natural fibres as well such as lower mechanical, thermal and physical properties than synthetic fibres reinforced composite [7]. Natural fibre reinforced polymer composites are sensitive to water absorption and humidity which can affect the dimension stability of these composites. Water absorption behavior may influence the mechanical strength and compatibility between fibre and matrix and lead to poor stress transfer efficiencies from matrix to reinforcement [8].

Mechanism of water absorption in fibre composites is based on three ways; first method is diffusion method [9], water molecules flow into micro-cracks of polymer chains. Second method is capillary flow $[4,10]$; water flow along with the interface if interfacial bonding of fibre and matrix is weak. Last mechanism is moisture content; storage of water in micro-cracks present in both polymer and natural fibre [11]. Study of water absorption in natural fibre composite is necessary for different applications such as outdoor component, waste water treatment, packaging and building industry. In natural fibre reinforcement, fibre absorb water due to many reasons such as temperature, amount of fibre, orientation of reinforcement, fibre characteristics, area of exposed surfaces, diffusivity, and surface protection [12].

Sugar palm fibres (SPF) are extracted from a very versatile sugar palm tree, and almost every part of this tree can be used in various applications. SPF are known to resist higher amounts of degradability in comparison to various other fibres [13]. During the past few years, various studies have explored the use of SPF as a composite reinforcement [1,14,15]. The exploration of the properties of SPF reinforced composites (SPFC) is of high importance to make them more suitable for their potential modern applications such as roofing material, tertiary structures, etc. Various studies were performed to enhance the properties of SPFC with chemically modifying the SPF [16,17].

However, studies on the effect of introducing fillers into the SPF reinforced composites remain unexplored. Therefore, this study aims to investigate the effect of fillers on SPFC. The filler used in this study is silica aerogel (SA). Aerogels are nanoporous materials with exceptional physical and thermal properties [10]. The mesoporous structure of SA offers a large surface area, which can improve the properties by promoting interfacial adhesion within a composite, 
with a considerably low amount of loading $[18,19]$. The SA filler used in this study is derived from rice husk, which is otherwise a waste material, making it both economically and environmentally beneficial product. The features of this SA are considered to be of higher quality in comparison to commercially available tetra-ethoxy-silane (TEOS) based SA [20]. In this paper, the effects of adding various concentrations of SA on the water absorption and thickness swelling properties of SPF/UPE composites were studied.

\section{MATERIALS AND METHOD}

\section{A. Materials}

SPF were extracted from sugar palm trees in Kampung Kuala Jempol, Negeri Sembilan, Malaysia. These fibres grow around the trunk of the trees and are in a naturally woven state. General purpose polyester resin was used as the binder for fabrication of the composites. Unsaturated polyester (UPE) commercially known as "REVERSOL P9509" was supplied by Bintang Timur Sdn Bhd, Malaysia. The catalyst used for curing UPE was Methyl Ethyl Ketone Peroxide (MEKP) which also acquired from the same supplier. SA was used as the filler and was produced from rice husk, supplied by Maerotech Sdn Bhd, Malaysia. This SA was delivered in a white powder form and was used without any further modifications. As reported in previous studies, this mesoporous SA has an approximate specific surface area of $900 \mathrm{~m} 2 / \mathrm{g}$ with nanoscale dimensions ranging from $20 \mathrm{~nm}$ to $50 \mathrm{~nm}$ [21]. Its melting and boiling temperatures were reported to be between $1700^{\circ} \mathrm{C}$ and $2230^{\circ} \mathrm{C}$ respectively.

\section{B. Fabrication of Composite}

SPF were thoroughly washed with tap water to remove any excessive impurities and dried at room temperature for at least 1 to 2 days. These dried fibres were then stacked to obtain an approximate $30 \%$ weight fraction of the composite for fabrication. SA powder, with $1 \%$ to $5 \%$ weight percentage, was mechanically stirred in UPE resin for 60 minutes at 500 rpm. The mixture was then left to settle for another 30 minutes to remove excess air bubbles. $1 \%$ MEKP was mixed in the resin mixture and stirred with a wooden stick for approximately 30 seconds. Next, the fibres were placed in the mould with the dimensions of $150 \times 150 \times 3 \mathrm{~mm} 3$, and the resin mixture was slowly poured on to the fibres. A steel roller was used to evenly distribute the resin in the fibres and to assist in the removal of air bubbles.

The mould was then closed and left to settle for another 2 to 3 minutes to allow for the resin to flow throughout the mould. Later, the mould was placed in a 40 tons hydraulic hot press machine and pressed at $80^{\circ} \mathrm{C}$. After 30 minutes the mould was taken out from the machine and left for another 1 to 2 days to allow for post curing. Table 1 shows the weight fraction for components of the fabricated composites.

Table 1. Weight fraction of SPF reinforced unsaturated polyester hybrid composites

\begin{tabular}{ccccc}
\hline SN. & $\begin{array}{c}\text { Notatio } \\
\mathbf{n}\end{array}$ & $\begin{array}{c}\text { Sugar } \\
\text { Palm } \\
\text { Fibres } \\
(\mathbf{w t} \%)\end{array}$ & $\begin{array}{c}\text { Unsaturated } \\
\text { Polyester } \\
(\mathbf{w t} \%)\end{array}$ & $\begin{array}{c}\text { Silica } \\
\text { Aerogel } \\
\text { (wt\%) }\end{array}$ \\
\hline 1 & $0 \%$ & 30 & 70 & 0 \\
2 & 1\% SAC & 30 & 69 & 1 \\
3 & $2 \%$ SAC & 30 & 68 & 2 \\
4 & $3 \%$ SAC & 30 & 67 & 3 \\
5 & 4\% SAC & 30 & 66 & 4 \\
6 & 5\% SAC & 30 & 65 & 5 \\
\hline
\end{tabular}

\section{Characterizations}

To investigate the water absorption and thickness swelling characteristics, the composites were immersed in distilled water and the changes in dimensions were recorded. The mass and thickness of each composite was measured per the following schedule for the first week, at: $1 \mathrm{st}, 3 \mathrm{rd}$, 5th and 7th day. Later, the readings were taken on a weekly basis until the 3 rd week and bi-weekly for the rest of immersion time. The specimens were exposed to water absorption for a total of 90 days and calculated according to the equation 1 and 2 .

Water absorption $(\%)=[(\mathrm{Wn}-\mathrm{Wd}) / \mathrm{Wd}] \mathrm{X} 100 \quad \ldots .(1)$

where, $\mathrm{Wn}$ is the weight of composites samples after immersion and $\mathrm{Wd}$ is the weight of the composite samples before immersion.

Thickness Swelling $(\%)=[(\mathrm{T} 1-\mathrm{T} 0) / \mathrm{T} 0] \mathrm{X} 100 \ldots(2)$

where, T1 is the thickness after soaking and T0 is the thickness before soaking

\section{RESULTS AND DISCUSSION}

\section{A. Water Absorption}

The water absorption of composites relative to immersion time is displayed in Figure 1. It can be observed that all the investigated composites showed a typical trend of moisture uptake for NFC, where the absorption increases with increase in time of exposure until it becomes nearly stagnant [22, 23]. In general, a varying water uptake rate and capacity were observed for the composites with and without SA. A sudden increase in water absorption was seen during the first few days of the immersion time. The rate of water absorption slowly decreased with further exposure time. It can be seen that the rise in water absorption is influenced by the increased concentration of SA. The primary reason of this characteristic is the hydrophilic nature of SA with hydroxyl groups on its surface. A composite acts hydrophilic when the silica surface of the filler is hydroxylase [24]. Hydrophilic nature of the fillers attracts and facilitates the penetration of water within the composite as described by previous researchers [3, 23]. The existence of additives in the composite may cause the creation of higher void content due to additional steps

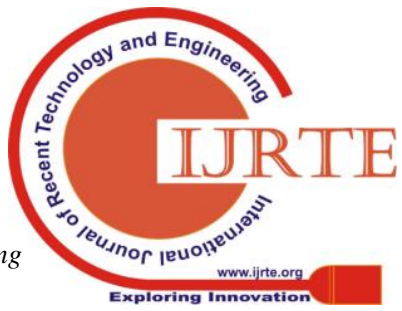


involved during the fabrication process [24]. Mesoporous structure of SA particles can also play a hand in greater water absorption by allowing the natural fibres to swell at a higher degree due to induced flexible tendencies in the matrix by highly porous and less dense SA content [25]. These aspects resulted in a higher capacity of SA filled composites to absorb water in comparison to composites without SA.

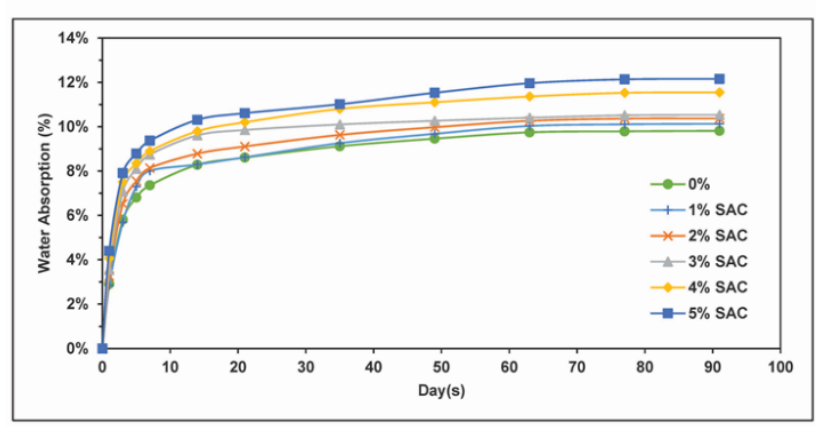

Figure 1. Water absorption behaviour of composites with and without various SA content

\section{B. Thickness swelling}

In this section, the changes in thickness of the composites immersed in water were recorded as shown in Figure 2. The swelling of the composites showed very similar changes to water absorption characteristics in the previous section.

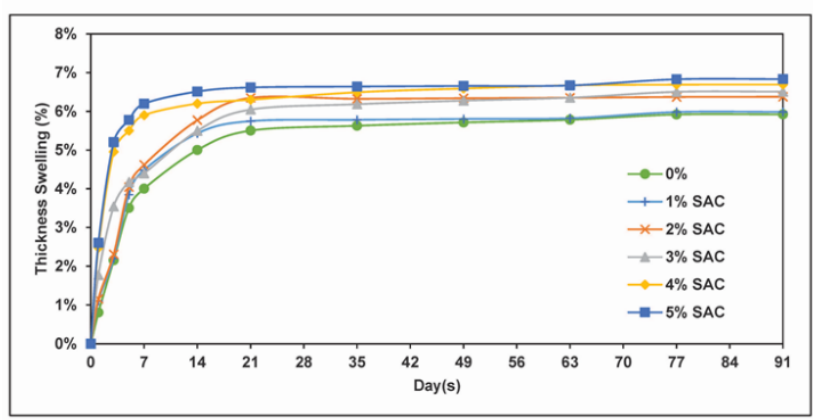

Figure 2. Thickness swelling behavior of composites with and without various SA concentrations

All composites with SA swell at a greater degree compared to the $0 \%$ composite. $0 \%$ composite recorded the lowest final rise in thickness of $5.92 \%$ while $5 \%$ SAC composite showed the highest final swelling of up to $6.83 \%$. Higher SA loading (4\% and 5\%) resulted in a lesser time needed to reach swelling stability, which occurred within the first two weeks of exposure, compared to a lower SA content and $0 \%$ composite. The increased rate of thickness swelling can be attributed to higher water absorption with an increase in SA content. The increase in swelling due to the addition of SA demonstrated that there is an increase in the degree of flexibility in the otherwise stiff and brittle binders. A previous researcher also showed a similar trend of thickness swelling with the addition of SA in epoxy [24]. There is a small bump in thickness swelling between the 10th and 11th week in most of the composites. This may be the result of crack propagation due to high water absorption of fibres, which induced higher stress within the matrix [25].

\section{CONCLUSION}

The effect of SA addition on water absorption capabilities of sugar palm reinforced polyester composites was investigated in this study. It was observed that SA had a significant effect on the water absorption characteristics of the composites. It can be concluded that the infusion of SA resulted in a higher volume of water uptake due to the increased amount of hydrophilic constituents of the composite. Therefore, with every increment in concentration of SA a higher value of water absorption was observed. Thickness swelling was also considerably affected with the increase of SA loading in the composites. 5\% SA content was concluded to have the highest capacity of thickness swelling, while $1 \%$ SA had the least swelling among SA infused SPF/UPE composites. However, the composite without SA was found to have the least water absorption and thickness swelling properties in comparison to all the SA filled composites. This composite is proposed to make roof top becouse raw materials is easily available in malsiya, strength is very high and it have poor water holding capacity.

\section{ACKNOWLEDGEMENT}

The authors extend their gratitude to the Ministry of Higher Education for providing HICOE Grant No: 6369108 to INTROP, Universiti Putra Malaysia (UPM), to support this research.

\section{REFERENCES}

[1] M. Sanyang, S. Sapuan, M. Jawaid, M. Ishak, and J. Sahari, "Recent developments in sugar palm (Arenga pinnata) based biocomposites and their potential industrial applications: A review," Renewable and Sustainable Energy Reviews, vol. 54, (2016), pp. 533-549.

[2] M. Asim, M. Jawaid, K. Abdan, M. Ishak, and O. Alothman, "Effect of Hybridization on the Mechanical Properties of Pineapple Leaf Fiber/Kenaf Phenolic Hybrid Composites," Journal of Renewable Materials, vol. 6, (2018), pp. 38-46,.

[3] K. Senthilkumar, N. Saba, N. Rajini, M. Chandrasekar, M. Jawaid, S. Siengchin, et al., "Mechanical properties evaluation of sisal fibre reinforced polymer composites: a review," Construction and Building Materials, vol. 174, (2018), pp. 713-729.

[4] M. Asim, M. Paridah, M. Jawaid, M. Nasir, and N. Saba, "Physical and flammability properties of kenaf and pineapple leaf fibre hybrid composites," in IOP Conference Series: Materials Science and Engineering, (2018), pp. 012018.

[5] R. Siakeng, M. Jawaid, H. Ariffin, S. Sapuan, M. Asim, and N. Saba, "Natural fiber reinforced polylactic acid composites: A review," Polymer Composites, vol. 40, (2019), pp 446-463.

[6] I. Aji, S. Sapuan, E. Zainudin, and K. Abdan, "Kenaf fibres as 
reinforcement for polymeric composites: a review," International Journal of Mechanical and Materials Engineering, vol. 4, (2009), pp. 239-248

[7] M. Asim, M. Jawaid, M. Nasir, and N. Saba, "Effect of fiber loadings and treatment on dynamic mechanical, thermal and flammability properties of pineapple leaf fiber and kenaf phenolic composites," Journal of Renewable Materials, vol. 6, (2018), pp. 383-393.

[8] M. Asim, M. Paridah, N. Saba, M. Jawaid, O. Y. Alothman, M. Nasir, et al., "Thermal, physical properties and flammability of silane treated kenaf/pineapple leaf fibres phenolic hybrid composites," Composite Structures, vol. 202,( 2018), pp 1330-38.

[9] M. Shirangi and B. Michel, "Mechanism of moisture diffusion, hygroscopic swelling, and adhesion degradation in epoxy molding compounds," in Moisture sensitivity of plastic packages of IC Devices, ed: Springer, (2010), pp. 29-69.

[10] D. Ge, L. Yang, Y. Li, and J. Zhao, "Hydrophobic and thermal insulation properties of silica aerogel/epoxy composite," Journal of Non-Crystalline Solids, vol. 355, (2009), pp. 2610-2615.

[11] H. Dhakal, Z. Zhang, and M. Richardson, "Effect of water absorption on the mechanical properties of hemp fibre reinforced unsaturated polyester composites," Composites science and technology, vol. 67, (2007), pp. 1674-1683.

[12 ]L. U. Devi, S. Bhagawan, K. M. Nair, and S. Thomas, "Water absorption behavior of PALF/GF hybrid polyester composites," Polymer Composites, vol. 32, (2011), pp. 335-346.

[13] M. Ishak, S. Sapuan, Z. Leman, M. Rahman, U. Anwar, and J. Siregar, "Sugar palm (Arenga pinnata): Its fibres, polymers and composites," Carbohydrate polymers, vol. 91, (2013), pp. 699-710.

[14] I. Mukhtar, Z. Leman, M. R. Ishak, and E. S. Zainudin, "Sugar palm fibre and its composites: a review of recent developments," BioResources, vol. 11, (2016), pp. 10756-10782.

[15] A. Ticoalu, T. Aravinthan, and F. Cardona, "A review on the characteristics of gomuti fibre and its composites with thermoset resins," Journal of Reinforced Plastics and Composites, vol. 32, (2013), pp. 124-136.

[16] D. Bachtiar, S. Sapuan, E. Zainudin, A. Khalina, and K. Dahlan, "Thermal properties of alkali-treated sugar palm fibre reinforced high impact polystyrene composites," Pertanika Journal of Science \& Technology, vol. 21, (2013), pp. 141-150.

[17]B. Rashid, Z. Leman, M. Jawaid, M. J. Ghazali, and M. R. Ishak, "Influence of treatments on the mechanical and thermal properties of sugar palm fibre reinforced phenolic composites," BioResources, vol. 12, (2017), pp. 1447-1462.

[18] N. Kim, H. Hwang, J. Lee, K. Choi, and I. Park, "Silica aerogel for the mechanical reinforcement of thermoset epoxy polymers," in Proceedings of the 18th International Conference on Composite Materials (South Korea), Jeju. International Committee on Composite Materials, (2011), pp. 318-324.

[19] R. M. Shahroze, M. R. Ishak, M. S. Salit, Z. Leman, M. Asim, and M. Chandrasekar, "Effect of Organo-Modified Nanoclay on the Mechanical Properties of Sugar Palm
Fiber-reinforced Polyester Composites," BioResources, vol. 13, (2018), pp. 7430-7444.

[20]H. Hamdan, "Nanomaterials as catalysts in the production of fine chemicals," Akta Kimindo, vol. 1, (2005), pp. 1-10.

[21] I. Babaei, M. Madanipour, M. Farsi, and A. Farajpoor, "Physical and mechanical properties of foamed HDPE/wheat straw flour/nanoclay hybrid composite," Composites Part B: Engineering, vol. 56, (2014), pp. $163-170$.

[22] C. Srivabut, T. Ratanawilai, and S. Hiziroglu, "Effect of nanoclay, talcum, and calcium carbonate as filler on properties of composites manufactured from recycled polypropylene and rubberwood fiber," Construction and Building Materials, vol. 162, (2018), pp. 450-458.

[23] I. Babaei, M. Madanipour, M. Farsi, and A. Farajpoor, "Physical and mechanical properties of foamed HDPE/wheat straw flour/nanoclay hybrid composite," Composites Part B: Engineering, vol. 56, (2014), pp. 163-170.

[24]T. Väisänen, O. Das, and L. Tomppo, "A review on new bio-based constituents for natural fiber-polymer composites," Journal of Cleaner Production, vol. 149, (2017), pp. 582-596.

[25]M. Asim, M. Jawaid, K. Abdan, and M. Ishak, "Dimensional stability of pineapple leaf fibre reinforced phenolic composites," in AIP Conference Proceedings, (2017), p. 030016.

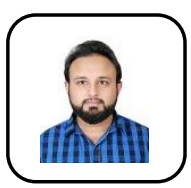

R.M. Shahroze is a Postgraduate researcher in Faculty of Engineering, Universiti Putra Malaysia. $\mathrm{He}$ has successfully published around 10 publications including articles in international journals, book chapters, conference papers.

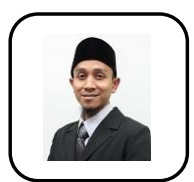

M.R. Ishak is a senior lecturer in the Department of Aerospace Engineering, Universiti Putra Malaysia. To date, he has around 80 journal, 23 conference papers and various book chapters to his credit.

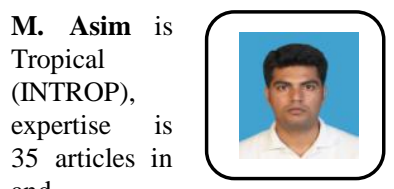

Post-Doctoral fellow in Institute of Forestry and Forest Products University Putra Malaysia. His area of polymer composites. He has published international journals, book chapters proceedings.

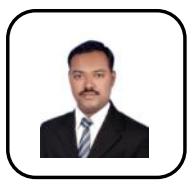

M Chandrasekar has completed his Doctorate in Aerospace Engineering from Universiti Putra Malaysia His $\mathrm{PhD}$ research was funded by research grant from Ministry of Education, Malaysia. His field of interest is bio-composite and fibre metal laminates.

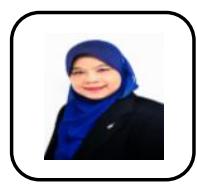

Paridah Md Tahir is a professor in Institute of Tropical Forestry and Forest Products (INTROP), University Putra Malaysia. Her area of expertise is Wood Chemistry. She has published more than 250 articles in numerous journals, co-authored 6 books and more than 100 chapters in book, proceedings, technical and consultation reports.

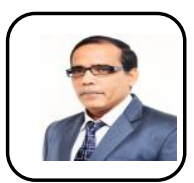

M. Jawaid is currently working as Fellow Researcher at Institute of Tropical Forestry and Forest Products (INTROP), Universiti Putra Malaysia. His area of expertise is polymer science. he has published 8 books, 25 book chapters, and more than 250 International journal papers. 